\title{
Rehmannia glutinose Ameliorates Renal Function in the Ischemia/ Reperfusion-Induced Acute Renal Failure Rats
}

\author{
Dae Gill Kang, Eun Jin Sohn, Mi Kyoung Moon, Yun Mi Lee, and Ho Sub LeE* \\ Professional Graduate School of Oriental Medicine and Medicinal Resources Research Institute (MeRRI), Wonkwang \\ University; Iksan, Jeonbuk, 570-749, Republic of Korea. $\quad$ Received December 23, 2004; accepted June 14, 2005
}

\begin{abstract}
The present study was designed to examine whether aqueous extract of steamed root of Rehmannia glutinose (ARR) has an ameliorative effect on renal functional parameters in association with the expressions of aquaporin 2 (AQP 2), Na,K-ATPase, and heme oxygenase-1 (HO-1) in the ischemia-reperfusion induced acute renal failure (ARF) rats. Polyuria caused by down-regulation of renal AQP 2 in the ischemia-induced ARF rats was markedly restored by administration of ARR $(200 \mathrm{mg} / \mathrm{kg}$, p.o. $)$ with restoring expression of AQP 2 in the kidney. The expressions of $\mathrm{Na}, \mathrm{K}$-ATPase $\alpha 1$ and $\beta 1$ subunits in the renal medullar and cortex of the ARF rats were also restored in the ARF rats by administration of ARR. On the other hand, administration of ARR lowered the renal expression of HO-1 up-regulated in rats with ischemia-induced ARF. The renal functional parameters including creatinine clearance, urinary sodium excretion, urinary osmolality, and solute-free reabsorption were also markedly restored in ischemia-ARF rats by administration of ARR. Taken together, these data indicate that RSR ameliorates renal defects in rats with ischemia-induced ARF.
\end{abstract}

Key words Rehmannia glutinose; acute renal failure (ARF); renal function

A steamed root of Rehmannia glutinose LiBosch. (Scrophulariaceae), called 'Sukjihwang' in Korea, 'Jukujio' in Japan, and 'Shudihuang' in China, has been widely used in East Orient for the treatment of renal diseases, inflammatoryrelated diseases, or diabetes mellitus. In Oriental medicinal concept, this root has been used for nourishing the Yin deficiency of liver, kidney, and heart. There have been many reports in the pharmacological efficacy of ARR with anti-allergic reaction, ${ }^{1)}$ anti-oxidant effect, ${ }^{2)}$ anti-inflammatory effect, ${ }^{3)}$ hypoglycemic effect, ${ }^{4)}$ and activate bone metabolism. ${ }^{5)}$ The main constituents of ARR are sitosterol and mannitol; other constituents include a small amount of strigmaterol, campesterol, catapol, rehmannin, 2-formyl-5-hydroxymethylfurane, rehmaglutin D. 6 ,7)

The kidney plays a central role in the regulation of body salt and water balance. Disregulation of salt and/or water transporters in the kidney is responsible for altered salt and water balance in severe pathophysiological states including nephrotic syndrome,${ }^{8)}$ nephrogenic diabetes insipidus, ${ }^{9}{ }^{9}$ hypertension, ${ }^{10)}$ and acute renal failure (ARF) ${ }^{11)}$ Among them, $\mathrm{ARF}$ is a syndrome defined as an acute reduction in renal function. ARF is commonly due to acute tubular necrosis with usually reversible loss of renal function incurred from ischemic or nephrotoxic insults. Experimental ARF induced by ischemia-reperfusion in rats exhibits characteristic structural alterations in renal tubule epithelia in association with an impairment of urinary concentrating mechanism. ${ }^{12)}$ Furthermore, ARF caused by renal ischemia/reperfusion is typically characterized by a nonoliguria, a severe reduction in glomerular filtration rate (GFR), a variable fall in renal blood flow, and a decreasing in the urinary concentrating ability. ${ }^{13-15)}$ Although ARR is widely used in Oriental medicine for the treatment of renal diseases, there is little experimental data about beneficial effects of ARR on renal diseases in vivo. Moreover, ARR is the most important component in the Yukmijihwang-tang (called 'liuweidihuang-tang' in China) of which Oriental medicinal decoction consists of six medicinal plants used for the treatment of renal diseases. ${ }^{16)}$ Therefore, in the present study, we examined the effects of ARR on renal function and the expression levels of proteins affecting renal function in the ischemia/reperfusion-induced ARF rats.

\section{MATERIALS AND METHODS}

Preparation of ARR The steamed root of $R$. glutinose was purchased from the herbal medicine co-operative association of Junbuk Province (Iksan, Korea), in September 2003. Voucher specimen (NO. BDR 30) has been deposited in the Herbarium of the Professional Graduated School of Oriental Medicine, Wonkwang University (Iksan, Korea). The steamed root of R. glutinose $(600 \mathrm{~g})$ was boiled with 21 of distilled water at $100^{\circ} \mathrm{C}$ for $2 \mathrm{~h}$. The extract was centrifuged $2500 \times \boldsymbol{g}$ for $20 \mathrm{~min}$ at $4{ }^{\circ} \mathrm{C}$, and resulting supernatant was lyophilized to produce powder $(67.2 \mathrm{~g})$, and kept at $4{ }^{\circ} \mathrm{C}$. For in vivo experiments, this formulation was dissolved in distilled water and then diluted to the appropriate doses before oral administration

Animals All animal procedures were carried out in accordance with the National Institute of Health Guide for the Care and Use of Laboratory Animals (NIH Publication No. 85-23, revised 1996) and were approved by the Institutional Animal Care and Utilization Committee for Medical Science of Wonkwang University. Male Sprague-Dawley rats (weighing 200 to $220 \mathrm{~g}$ ) were purchased from Korean Experimental Animals Co. (Daejeon, Korea) and used in this study. To induce ischemia/reperfusion ARF, both renal arteries were clamped for $45 \mathrm{~min}$ under sodium pentobarbital anesthesia $(50 \mathrm{mg} / \mathrm{kg}$, i.p.). Control rats underwent sham operation without clamping the renal arteries. They were returned to the metabolic cage and were kept to recover for $4 \mathrm{~d}$. Three groups of animals consisted of eight rats each were investigated: sham-operated control group administered with distilled water, bilaterally clamped ARF group, third group consisted ischemia/reperfusion-induced ARF rats that were orally administered with ARR $(200 \mathrm{mg} / \mathrm{kg} / \mathrm{d})$ for $4 \mathrm{~d}$. The optimal protocol including experimental term and dose of ARR was determined from our previous study. ${ }^{17)}$ On the day of experiment, the trunk blood was collected by decapitation 
Table 1. Comparisons of Renal Function among the Experimental Groups

\begin{tabular}{|c|c|c|c|c|c|}
\hline & $\mathrm{UV}(\mathrm{ml} / \mathrm{kg} / \mathrm{d})$ & $\mathrm{UNaV}(\mu \mathrm{Eq} / \mathrm{min} / \mathrm{kg})$ & $\mathrm{UKV}(\mu \mathrm{Eq} / \mathrm{min} / \mathrm{kg})$ & $\mathrm{UClV}(\mu \mathrm{Eq} / \mathrm{min} / \mathrm{kg})$ & $\begin{array}{c}\text { Uosmol } \\
\left(\mathrm{mosmol} / \mathrm{kg} \mathrm{H}_{2} \mathrm{O}\right)\end{array}$ \\
\hline $\mathrm{CON}$ & $40.2 \pm 2.8$ & $4.95 \pm 0.25$ & $10.11 \pm 0.41$ & $7.08 \pm 0.42$ & $1337 \pm 165$ \\
\hline $\mathrm{ARF}$ & $83.6 \pm 2.5 * *$ & $3.36 \pm 0.46^{*}$ & $9.69 \pm 0.59$ & $6.01 \pm 0.69$ & $725 \pm 92 * *$ \\
\hline $\mathrm{ARF} / \mathrm{ARR}$ & $68.5 \pm 4.5^{\#}$ & $4.30 \pm 0.20^{\#}$ & $8.64 \pm 0.47$ & $6.13 \pm 0.65$ & $1211 \pm 110^{\#}$ \\
\hline
\end{tabular}

Values are means \pm S.E. $(n=6) . * p<0.05, * * p<0.01$, compared with control group (CON). ${ }^{2} p<0.05$, compared with ischemia-reperfusion-induced ARF group (ARF).

without anesthesia in a prechilled tube containing $1 \mathrm{mg} / \mathrm{ml}$ ethylenediamine tetraacetic acid (EDTA) for the determination of plasma creatinine and electrolytes.

Monitoring of Renal Function Each group of rats was maintained in separate metabolic cages for $4 \mathrm{~d}$, allowing quantitative urine collections and measurements of water intake. On the day before sacrifice, 24-h urine samples were collected (between 09:00 and 10:00 a.m.) for the determination of the levels of creatinine, sodium, potassium, osmolality, and other parameters of renal function. Plasma levels of sodium, potassium, osmolality, and creatinine were also measured. On the day of sacrifice, blood was collected immediately following decapitation for the measurement of sodium and potassium ion levels, osmolality, and creatinine concentration in the plasma. The concentrations of ions were measured using an electrolyte analyzer (NOVA 4, Biochemical, Waltham, MA, U.S.A.). Osmolality was measured using an Advanced CRYOMATIC ${ }^{\mathrm{TM}}$ osmometer (Model 3900, Advanced Instruments Inc., Norwood, MS, U.S.A.). Creatinine concentrations (Ccr) of plasma and urine were measured by colorimetric method using a spectrophotometer (Miloton Roy, Rochester, NY, U.S.A.). Solute-free water reabsorption $\left(\mathrm{T}^{\mathrm{c}} \mathrm{H}_{2} \mathrm{O}\right)$ was calculated by the following formula: $\mathrm{T}^{\mathrm{c}} \mathrm{H}_{2} \mathrm{O}=$ $\mathrm{V} \times($ Uosmol/Posmol-1), where $\mathrm{V}$ is urine volume, Uosmol is urinary osmolality, and Posmol is plasma osmolality.

Protein Preparation Kidneys were immediately isolated after decapitation of rats, rapidly frozen in liquid $\mathrm{N}_{2}$, and stored at $-72{ }^{\circ} \mathrm{C}$ until assay. The inner medulla, outer medulla, and cortex from frozen kidney tissues were dissected and homogenized with Polytron homogenizer (KriensLuzern, Switzerland) at $3000 \mathrm{rpm}$ in a solution containing $250 \mathrm{mmol} / 1$ sucrose, $1 \mathrm{mmol} / 1$ EDTA, $0.1 \mathrm{mmol} / 1$ phenylmethylsulfonyl fluoride (PMSF, freshly prepared) and $20 \mathrm{mmol} / 1$ potassium phosphate buffer $(\mathrm{pH}$ 7.6). Large tissue debris and nuclear fragments were removed by two low speed spins in succession $(1000 \times \boldsymbol{g}, 5 \mathrm{~min} ; 10000 \times \boldsymbol{g}, 10 \mathrm{~min})$ at $4{ }^{\circ} \mathrm{C}$. Supernatants from these low speed spins were ultracentrifuged at $100000 \times \boldsymbol{g}$ for $1 \mathrm{~h}$ at $4^{\circ} \mathrm{C}$. The resultant pellet was resuspended for Western blotting of aquaporin (AQP) 2 . $\mathrm{Na}, \mathrm{K}$-ATPase $\alpha 1$ - and $\beta 1$-subunits and HO-1. The protein concentration was determined by the method of Bradford ${ }^{18)}$ with bovine serum albumin as a standard.

Western Blot Analyses Protein samples $(60 \mu \mathrm{g}$; renal cortex, $20 \mu \mathrm{g}$; outer medulla, $10 \mu \mathrm{g}$; inner medulla) were electrophoretically fractionated with a discontinuous system consisting of a $10 \%$ or $12.5 \%$ polyacrylamide resolving gel and 5\% stacking gel, followed by transfer to a nitrocellulose membrane at $20 \mathrm{~V}$ and $100 \mathrm{~mA}$ (current constant) overnight. The membrane was washed in Tris-based saline (TBS) buffer (pH 7.4) containing 0.1\% Tween-20 (TBST), blocked with $5 \%$ nonfat milk in TBST for $1 \mathrm{~h}$, and incubated with a $1: 750$ dilution of anti-rabbit polyclonal AQP 2 antibody (Alomone Lab., Jerusalem, Israel), anti-mouse monoclonal Na,K-ATPase $\alpha 1, \beta 1$ subunit antibody (Upstate biotechnology, Lake Placid, NY, U.S.A.), anti-goat polyclonal HO-1 antibody (Santa Cruz Biotechnolgy, Santa Cruz, CA, U.S.A.) in $2 \%$ nonfat milk/TBS for $1 \mathrm{~h}$ at room temperature. The membranes were then incubated with a horseradish peroxidase (HRP)-conjugated anti-rabbit IgG (1:1500), anti-mouse $\lg \mathrm{G}$ $(1: 1000)$ and anti-goat $\operatorname{lgG}(1: 1000)$ in $2 \%$ nonfat milk in TBS for an hour. The bound antibody was detected by enhanced chemiluminescence (Amersham, Buckingghamshire, U.K.) procedure. The relative protein expression levels were determined by analysing the signals captured on Chemi-doc image analyzer (Bio-Rad, Hercules, CA, U.S.A.).

Statistical Analysis Results were expressed as means S.E.M. The statistical significance of difference between the group means was determined using ANOVA and Dunnett's test. $p<0.05$ was considered statistically significant.

\section{RESULTS}

Renal Functional Parameters Table 1 summarizes the effects of ARR on changes in renal function in rats with ischemia/reperfusin-induced ARF. Urinary excretion rate (UV) was significantly increased in rats with ARF, which was markedly restored by oral administration of ARR. The urinary sodium excretion ( $\mathrm{UNaV}$ ) was decreased in rat with ARF compared with that of sham-operated control group. Oral administration of ARR also increased $\mathrm{UNaV}$ to nearly sham-operated control group. In contrast, there were no significant differences in urinary potassium excretion (UKV) and urinary chloride excretion (UCIV) among the all groups. Next, we determined the solute-free water reabsorption $\left(\mathrm{T}^{\mathrm{c}} \mathrm{H}_{2} \mathrm{O}\right)$ and creatinine clearance $(\mathrm{Ccr})$ on day 4 in rats from the three groups. Both solute-free water reabsorption and creatinine clearance were significantly decreased in ARF rats compared with those in control group $(p<0.05 v s$. control, respectively, Figs. 1A, B). Both of the parameters were significantly restored by an oral administration of ARR for $4 \mathrm{~d}$ $(p<0.05 v s$. control and ischemia/reperfusion-induced ARF group, respectively).

Aquaporin 2 Expression The expression level of AQP 2 protein was determined in the renal inner medulla, outer medulla, and cortex by Western blot analysis. The anti-AQP 2 antibody recognized $29 \mathrm{kDa}$ and 35 to $50 \mathrm{kDa}$ protein bands, corresponding to nonglycosylated and glycosylated AQP 2, respectively. The expression levels of AQP 2 in the inner (Fig. 2A) and outer medulla (Fig. 2B), and cortex (Fig. $2 \mathrm{C})$ were significantly decreased in rats with ischemia-ARF $(p<0.01 v s$. control group, respectively). This down-regulation in AQP 2 water channel was reverted by administration 

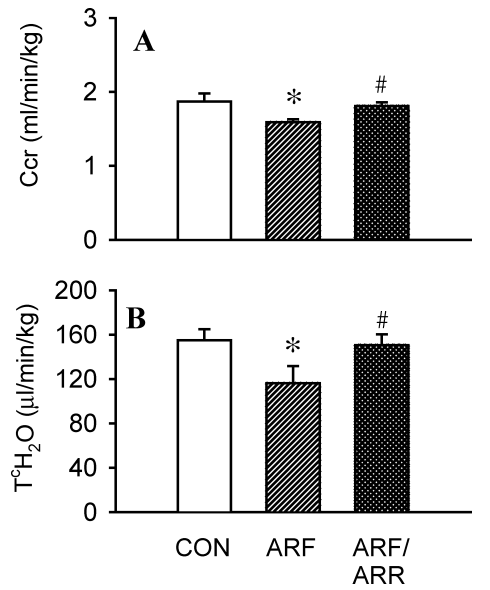

Fig. 1. Changes in Creatinine Clearance (Ccr, A), Solute-Free Water Reabsorption $\left(\mathrm{T}^{\mathrm{c}} \mathrm{H}_{2} \mathrm{O}, \mathrm{B}\right)$ in Rats with Control (CON), Ischemia/Reperfusion-Induced ARF (ARF), and Ischemia/Reperfusion-Induced ARF Administered with ARR (ARF/ARR; $200 \mathrm{mg} / \mathrm{kg} / \mathrm{d}$ ) for $4 \mathrm{~d}$

Each value represents the mean \pm S.E. of 6 experiments. $* p<0.05$, compared with control group; ${ }^{*} p<0.05$, compared with ARF group. of ARR (inner medullar; $p<0.05$, outer medullar and cortex $p<0.01 v s$. ischemia/reperfusion-induced ARF group, respectively).

Na,K-ATPase Expression Expression of $\alpha 1$ subunit of the $\mathrm{Na}, \mathrm{K}-\mathrm{ATPase}$, when assessed by Western blot analysis, was attenuated in the renal inner and outer medulla and cortex from ARF rats $(p<0.01 v s$. control, each, Fig. 3), but markedly restored by administration of ARR $(p<0.05 v s$. ARF, each). Administration of ARR also markedly restored the renal expression of $\alpha 1$ subunit of $\mathrm{Na}, \mathrm{K}$-ATPase suppressed in rats with ARF ( $p<0.05 v s$. ARF, Fig. 4).

Heme Oxygenase-1 (HO-1) Expression The results of the image-analysis of HO-1 band intensities expressed in arbitrary units are depicted in Fig. 4. The renal expression levels of HO-1 in the inner (Fig. 4A) and outer medullae (Fig. 4B), and cortex (Fig. 4C) were significantly increased in rats with ischemia/reperfusion-induced ARF $(p<0.01 v s$. control group, respectively). This up-regulation of HO-1 was reverted by administration of ARR in the kidney from ischemia-ARF $(p<0.01 v s$. ischemia/reperfusion-induced ARF
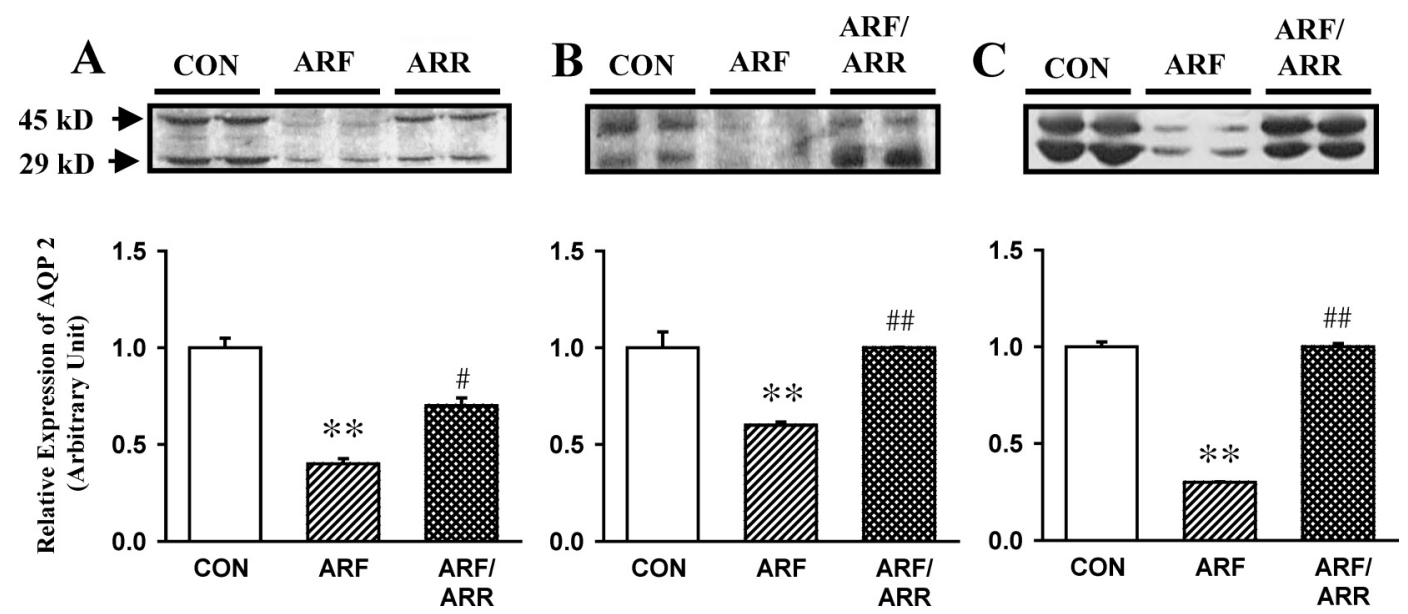

Fig. 2. Representative Western Blot and Corresponding Densitometric Analyses of AQP 2 Expression in the Renal Inner Medulla (A), Outer Medulla (B) and Cortex (C) of Control (CON), Ischemia/Reperfusion-Induced ARF (ARF), and Ischemia/Reperfusion-Induced ARF Administered with ARR (ARF/ARR; $200 \mathrm{mg} / \mathrm{kg} / \mathrm{d}$ ) Groups for $4 \mathrm{~d}$

Each data represents mean \pm S.E. of 6 experiments. $* * p<0.01$, compared with control; $\# p<0.05$, \# $p<0.01$, compared with ARF group.
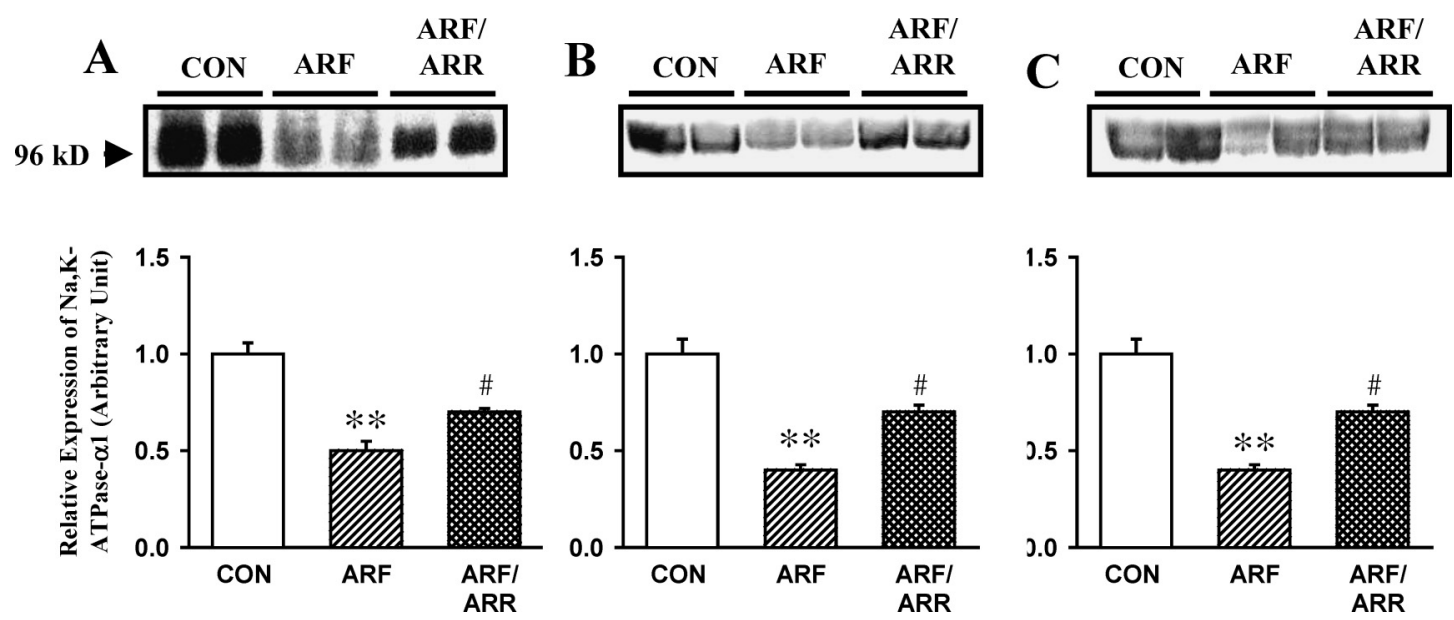

Fig. 3. Representative Western Blot and Corresponding Densitometric Analyses of Na,K-ATPase $\alpha 1$ Subunit Expression in the Renal Inner Medulla (A), Outer Medulla (B) and Cortex (C) of Control (CON), Ischemia/Reperfusion-Induced ARF (ARF), and Ischemia/Reperfusion-Induced ARF Administered with ARR (ARF/ARR; $200 \mathrm{mg} / \mathrm{kg} / \mathrm{d}$ ) Groups for $4 \mathrm{~d}$

Each data represents mean \pm S.E. of 6 experiments. $* * p<0.01 v$ s. control; ${ }^{*} p<0.05$, compared with ARF group. 

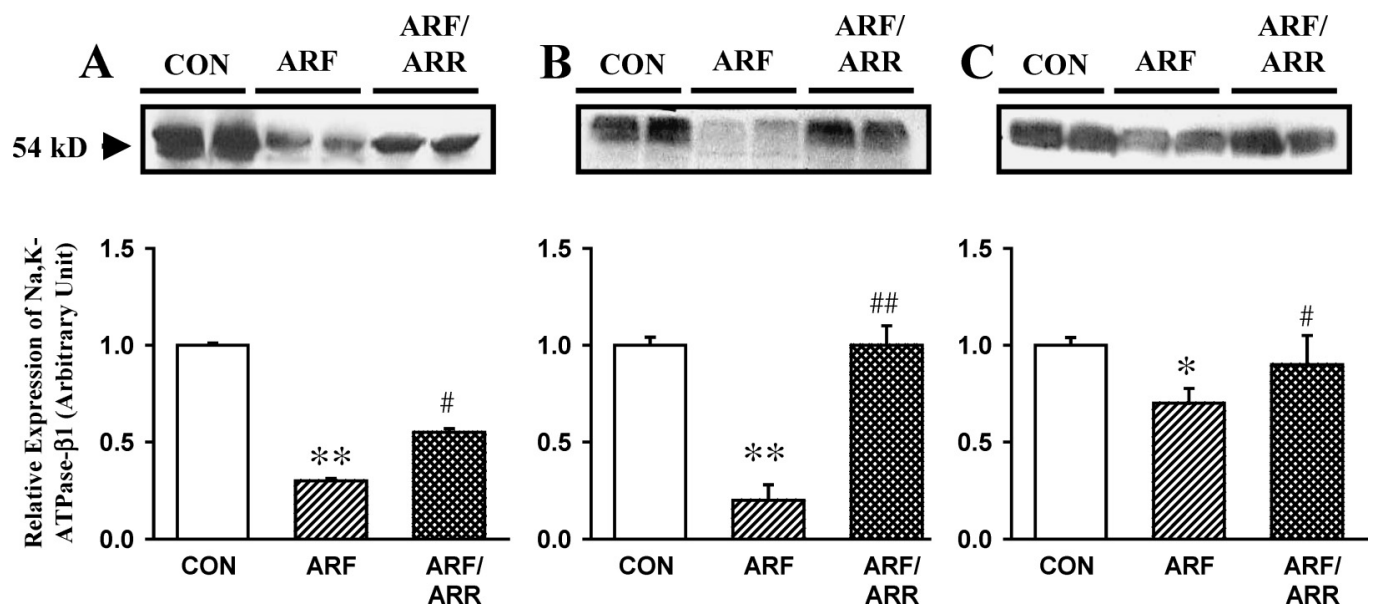

Fig. 4. Representative Western Blot and Corresponding Densitometric Analyses of Na,K-ATPase $\beta 1$ Subunit Expression in the Renal Inner Medulla (A), Outer Medulla (B) and Cortex (C) of Control (CON), Ischemia/Reperfusion-Induced ARF (ARF), and Ischemia/Reperfusion-Induced ARF Administered with ARR (ARF/ARR; $200 \mathrm{mg} / \mathrm{kg} / \mathrm{d}$ ) Groups for $4 \mathrm{~d}$

Each data represents mean \pm S.E. of 6 experiments. $* * p<0.01 v$ s. control; ${ }^{*} p<0.05$, \# $p<0.01$, compared with ARF group.
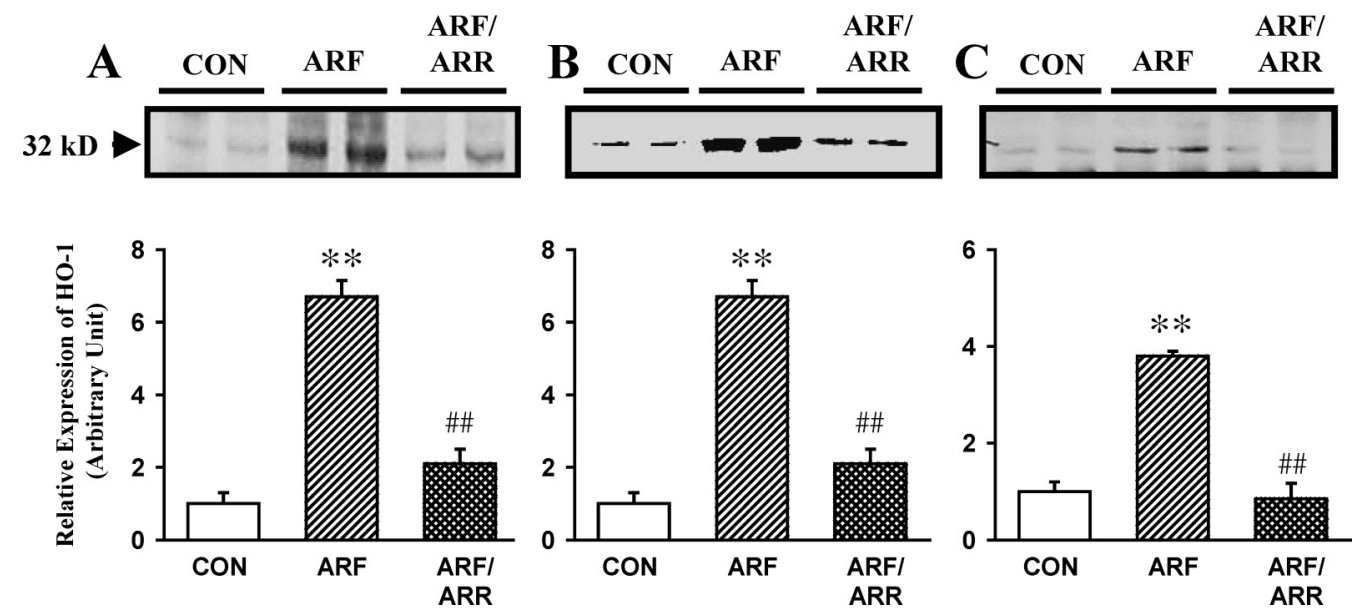

Fig. 5. Representative Western Blot and Corresponding Densitometric Analyses of HO-1 Expression in the Renal Inner Medulla (A), Outer Medullar (B) and Cortex (C) in Control (CON), Ischemia/Reperfusion-Induced ARF (ARF), and Ischemia/Reperfusion-Induced ARF Administered with ARR (ARF/ARR; $200 \mathrm{mg} / \mathrm{kg} / \mathrm{d}$ ) for $4 \mathrm{~d}$

Each data represents mean \pm S.E. of 6 experiments. $* * p<0.01 v$ s. control; \# $p<0.01$, compared with ARF group.

group, respectively).

\section{DISCUSSION}

The present study shows a protective action of ARR treatment in the renal derangement of rats with ischemia/reperfusion-induced ARF. In the present study, we examined the renal function of rats with ischemia/reperfusion-induced ARF showing a significant decline in renal function such as a marked decrease in creatinine clearance, urinary osmolality, and solute-free water reabsorption $\left(\mathrm{T}^{\mathrm{c}} \mathrm{H}_{2} \mathrm{O}\right)$ and increase urinary flow rates. These results indicate that ischemia/reperfusion-induced ARF causes an impairment of both urinary concentrating ability and glomerus filtration rate (GFR). These findings are not different from previously published data in which marked changes in renal function has been identified in the ischemia-ARF. ${ }^{13,14)}$ Water excretion is dependent on the balance between the GFR and the net rate of water absorption along the renal tubule. The present study shows that ischemia/reperfusion-induced ARF is characterized by nono- liguria in spite of reduction in creatinine clearance. In fact, it was well documented that ischemia-ARF is associated with increased urine flow due to suppression of tubular water reabsorption. ${ }^{13,14)}$ One important factor in this decrease in tubular water reabsorption is the osmotic diuresis that may accompany the elimination of urea and other species that accumulated in the blood due to the renal failure. The other important factor is the decreased expression of AQP 2 water channel that is responsible for the ability of water to penetrate the collecting duct epithelium, thus returning water to the blood stream in response to vasopressin. ${ }^{15)}$ It has been recently established that the epithelial water transport occurs through distinct channels called AQP. Among the multiple isoforms of AQP water channels, AQP 2 is dominant isoform in the collecting duct of the kidney. ${ }^{14,19)}$ The present study shows that the expression levels of AQP 2 in the inner and outer medullae and cortex of the kidney were significantly decreased in rats with ischemia/reperfusion-induced ARF rats. These results indicate that decreased level of renal AQP 2 may contribute to impairment in urinary concentration 
ability in rats with ischemia/reperfusion-induced ARF. However, ARR treatment groups markedly restored the renal AQP 2 expression in rats with ischemia/reperfusion-induced ARF, and this restoration paralleled with the salutary changes in renal function. Therefore, the ameliorative effect of urinary concentrating ability by ARR may be related to the up-regulation of the AQP 2 expression.

The proximal tubule is the site for the reabsorption of approximately two-thirds of the $\mathrm{Na}^{+}$that enters the tubular fluid by glomerular filtration. ${ }^{20)}$ A reduction in GFR in rats with ARF reduces the filtered load of sodium. This is consistent with the observation that the rate of urinary sodium excretion was decreased in ischemia-ARF rats. Sodium transport is mainly modulated by the enzyme, $\mathrm{Na}, \mathrm{K}$-adenosine triphosphatase (ATPase). The normal localization of $\mathrm{Na}, \mathrm{K}$ ATPase to the basolateral membrane is regulated by direct interactions with membrane-associated cytoskeletal protein. Following an ischemic insult proximal tubular cells exhibit a disruption of the actin-based cytoskeleton. ${ }^{21,22)} \mathrm{Na}, \mathrm{K}$-ATPase is an oligomeric enzyme composed of stoichiometric amounts of two major polypeptides, the $\alpha 1$ and $\beta 1$ subunit. The $\alpha 1$ subunit is a multispanning membrane protein that is responsible for the catalytic properties of the enzyme and $\beta 1$ subunit is a polypeptide that is essential for the normal activity. $^{23,24)}$ As many as four different $\alpha$-polypeptides and three distinct $\beta$-isoforms have been identified in the mammalian cells, but $\alpha 1$ and $\beta 1$ subunits are the major isoforms in the adult rat kidney. ${ }^{25)}$ The present study showed that the expression levels of $\mathrm{Na}, \mathrm{K}$-ATPase $\alpha 1$ and $\beta 1$ subunits in the outer medulla were significantly decreased in rats with ischemia/reperfusion-induced ARF. However, the reduced expression of the $\alpha 1$ and $\beta 1$ subunits of Na,K-ATPase were markedly reverted by administration with ARR in ischemia/reperfusion-induced ARF rats. The lesions in the glomerulus, proximal and distal tubules of renal cortex were restored by administration of ARR for $4 \mathrm{~d}$. Administration of ARR attributes a greatly beneficial effect against tubular and glomerular dysfunctions caused by ischemia-reperfusion ARF as indicated in actions of ARR on the Ccr.

As well known, reactive oxygen species (ROS) play a key role in renal ischemia/reperfusion injury. ${ }^{25,26)}$ ROS are produced by endogenous or infiltrating cells in the injured kidney, and contributes to acute renal injury or progressive renal damage. ${ }^{27}$ The expression of HO-1 in circumstances of stress represents an adaptive response that reduces the severity of oxidative damages. HO- 1 is inducted as a defense against oxidative stress. ${ }^{28)}$ Renal ischemia followed by reperfusion results in tubular epithelial cell injury mediated by oxidative stress. $\left.{ }^{29}\right)$ In general, oxidative stress such as hypoxia or ischemia may enhance intracellular accumulation of heme molecules, which participate in renal cell damage. ${ }^{30)}$ Under these circumstances, inducible HO-1 may be rapidly induced after stressful stimuli to protect renal cell from further degeneration. Two isoforms of HO have been extensively characterized; an inducible enzyme HO-1 and a constitutive isoform HO-2, respectively. The protective effects of $\mathrm{HO}-1$ against tissue injury caused by ischemia and oxidative stress have been well documented. ${ }^{28,31)}$ In the present experiment, HO-1 protein expression in the kidney from rats with ischemia-ARF was up-regulated compared to control group in the renal inner and outer medullae and cortex, respectively.
These findings are in line with previously published data showing a protective role of $\mathrm{HO}-1$ in the renal ischemia/ reperfusion injury. ${ }^{32)}$ ARR treatment in rats with ischemiaARF markedly prevented the up-regulation of HO-1. In this regard, ARR may have potent antioxidant effect against the impairment of renal function and injury cause by oxidative stress in ischemia/reperfusion-induced renal injury. This notion is in relation with previous report, ${ }^{2)}$ suggesting that ARR has a beneficial effect on preventing oxidative stress-induced renal tissue damages. In the previous studies, various antioxidant agents showed protection against renal injury induced by ischemia-reperfusion in rats. ${ }^{33-35)}$

In conclusion, administration of ARR, at dose of $200 \mathrm{mg} / \mathrm{kg} / \mathrm{d}$ for $4 \mathrm{~d}$, could ameliorate renal dysfunction and leads to up-regulation of protein levels of AQP 2 and $\mathrm{Na}, \mathrm{K}-$ ATPase and down-regulation of HO-1 in rats with ischemia/ reperfusion-induced ARF.

Acknowledgements This study was supported by the Brain Korea 21 Project (2004) and grants of the Oriental Medicine R\&D Project (03-PJ9-PG6-SO02-0001), Ministry of health \& Welfare, Republic of Korea.

\section{REFERENCES}

1) Kim H., Lee E., Lee S., Shin T., Kim Y., Kim J., Int. J. Immunopharmacol., 20, 231-240 (1998).

2) Jo S. I., Kor. J. Herbol., 18, 119-126 (2003)

3) Kim H. M., An C. S., Jung K. Y., Choo Y. K., Park J. K., Nam S. Y., Pharmacol. Res., 40, 171-176 (1999).

4) Zhang R., Zhou J., Jia Z., Zhang Y., Gu G., J. Ethnopharmacol., 90, 39-43 (2004).

5) Oh K. O., Kim S. W., Kim J. Y., Ko S. Y., Kim H. M., Baek J. H., Ryoo H. M., Kim J. K., Clin. Chim. Acta, 334, 185-95 (2003)

6) Kitagawa I., Fukuda Y., Taniyama T., Yoshikawa M., Yakugaku Zasshi, 115, 992-1003 (1995).

7) Anh N. T., Sung T. V., Franke K., Wessjohann L. A., Pharmazie, 58 593-595 (2003).

8) Fernandez-Llama P., Andrews P., Nielsen S., Ecelbarger C. A., Knepper M. A., Kidney Int., 53, 1244-1253 (1998).

9) Moses A. M., Miller M., Streeten D. H., Metabolism, 25, 697-721 (1976).

10) Lee J., Kang D. G., Kim Y., Clin. Exp. Hypertens., 22, 531-541 (2000).

11) Hsu C. H., Kurtz T. W., Rosenzweig J., Weller J. M., Nephron, 18, 326-332 (1977)

12) Brady H. R., Brenner B. M., Lieberthal W., "The Kidney," ed. by Brenner B. M., Rector J. F. C., Saunders, Philadelphia, PA, 1996, pp. $1200-1252$.

13) Fernandez-Llama P., Andrews P., Turner R., Saggi S., Dimari J., Kwon T. H., Nielsen S., Safirstein R., Knepper M. A., J. Am. Soc. Nephrol., 10, 1658-1668 (1999).

14) Kwon T. H., Frokiaer J., Fernandez-Llama P., Knepper M. A., Nielsen S., Am. J. Physiol., 277, F413-F427 (1999).

15) Kim S. W., Jeon Y. S., Lee J. U., Kang D. G., Kook H., Ahn K. Y., Kim S. Z., Cho K. W., Kim N. H., Han J. S., Choi K. C., Kidney Int., 57, $1643-1650$ (2000).

16) Yi N. Y., Chu W., Koang N. K., Chin. Med. J., 84, 433-436 (1965).

17) Kang D. G., Oh H., Sohn E. J., Hur T. Y., Lee K. C., Kim K. J., Kim T. Y., Lee H. S., Life Sci., 75, 1801-1816 (2004).

18) Bradford M. M., Anal. Biochem., 72, 248-254 (1976).

19) Nielsen S., DiGiovanni S. R., Christensen E. I., Knepper M. A., Harris H. W., Proc. Natl. Acad. Sci. U.S.A., 90, 11663-11667 (1993).

20) Weinberg J. M., Kidney Int., 39, 476-500 (1991).

21) Kellerman P. S., Bogusky R. T., Kidney Int., 42, 896-902 (1992).

22) Kellerman P. S., Clark R. A., Hoilien C. A., Linas S. L., Molitoris B. A., Am. J. Physiol., 259, F279-F285 (1990).

23) Blanco G., Detomaso A. W., Koster J., Xie Z. J., Mercer R. W., J. Biol. Chem., 269, 23420-23425 (1994). 
24) Blanco G.., Koster J. C., Mercer R. W., Proc. Natl. Acad. Sci. U.S.A., 91, 8542-8546 (1994).

25) Orlowski J., Lingrel J. B., J. Biol. Chem., 263, 10436-10442 (1988)

26) Baliga R., Ueda N., Walker P. D., Shah S. V., Am. J. Kidney Dis., 29, $465-477$ (1997).

27) Sussman M. S., Bulkley G. B., Method. Enzymol., 186, 711-723 (1990).

28) Nath K. A., Salahudeen A. K., J. Clin. Invest., 86, 1179-1192 (1990).

29) Bonventre J. V., Kidney Int., 43, 1160-1178 (1993).

30) Maines M. D., Mayer R. D., Ewing J. F., McCoubrey W. K., J. Parmacol. Exp. Ther., 264, 457-462 (1993).
31) Stocker R., Free Radical Res. Commun., 9, 101-112 (1990).

32) Agarwal A., Nick H. S., J. Am. Soc. Nephrol., 11, 965-973 (2000).

33) Blydt-Hansen T. D., Katori M., Lassman C., Ke B., Coito A. J., Iyer S., Buelow R., Ettenger R., Busuttil R. W., Kupiec-Weglinski J. W., J. Am. Soc. Nephrol., 14, 745-754 (2003).

34) Paller M. S., Hoidal J. R., Ferris T. F., J. Clin. Invest., 74, 1156-1164 (1984).

35) Bird J. E., Milhoan K., Wilson C. B., Young S. G., Mundy C. A., Parthasarathy S., Blantz R. C., J. Clin. Invest., 81, 1630-1638 (1988).

36) Shoskes D. A., Transplantation, 66, 147-152 (1998). 